\title{
Load combinations in performance-based designing of earthquake-resisting structures
}

\author{
Inna Kuznetsova ${ }^{1}$, Alexander Uzdin ${ }^{1, *}$ and Oypasha Sabirova ${ }^{1}$ \\ ${ }^{1}$ Emperor Alexander I St. Petersburg State Transport University, 190031, 9 Moskovsky pr., St. \\ Petersburg, Russia
}

\begin{abstract}
Load combinations for seismic and other loads are considered. To this aim the equiprobable sets of loads with the corresponding probabilities are analyzed. The combination of motor-car and seismic loads is considered in details. The log-normal distribution law was used as a distribution density functions for car load. The distribution of the earthquake event stream was taken according to Poisson's law, which makes it possible to estimate the design seismic intensity. In the frame of this intensity peak ground accelerations were estimated. The dependence of the combination coefficient of the seismic load on the combination coefficient of the motor-road load was obtained. The results obtained show, that combination coefficients in Performance Based Designing should be calculated separately for each input level. For the design earthquake and the maximum design earthquake the combination coefficients vary significantly. The values of the combination coefficients are determined mainly by the frequency of the design actions and to a lesser extent they depend on the seismic activity of the building site.
\end{abstract}

\section{Introduction}

At present transition to performance based designing (PBD) of earthquake-resistant structures is taking place in the world practice of earthquake engineering. Several limit states and the corresponding load levels are considered in the frame of PBD. In Russia this approach was called "designing structures with the given parameters of limit states"

The foundations of this approach were laid in the mid-1970s. The works of I.I. Goldenblat [1], Ya.M. Aizenberg and L.Sh. Kilimnik [2, 3] published in the former USSR should be noted. In the world D.J. Dowric [4] and D.Park [5] are considered to be the founders of PBD. PBD has been further developed by experts since the beginning of the 2000s [6,7] as the basis for Eurocode-8 [8], which recommended to use two levels of design input.

The first level corresponds to relatively weak inputs and frequent earthquakes (Design Earthquake, DE), which occur about once in 50-300 years. After such actions, the structure must operate in its standard regime. The limit state for these actions is a violation of normal operation (serviceability limit state, SLS). The second level corresponds to destructive

\footnotetext{
*Corresponding author : uzdin@mail.ru
} 
earthquakes called as the Maximum Design Earthquake (MDE), which occur about once in 1000-5000 years. The limit state for these actions is the destruction of the main loadbearing structures, leading to large social and economic losses.

While there is a great number of studies in the field of PBD, the issue of combinations of DE and MDE with other loads is not sufficiently described. In the first approximation, it seems logical to refer the DE to additional combinations of loads, and MDE to special ones. But in fact, the situation is more complicated and requires a separate consideration.

\section{State of art}

A general approach to the designation of the combination coefficients is considered in the investigations of well-known scientists V.V. Bolotin [9] A.R. Rzhanitsyn [10] etc. They considered the equiprobable sets of loads $\mathrm{Q}_{1}, \mathrm{Q}_{2}, \ldots \mathrm{Q}_{\mathrm{n}}$ with the corresponding probabilities $\mathrm{P}_{1}, \mathrm{P}_{2}, \mathrm{P}_{\mathrm{n}}$, for which condition (1) takes place

$$
\mathrm{P}_{1} \cdot \mathrm{P}_{2} \cdot \mathrm{P}_{3} \ldots \cdot \mathrm{P}_{\mathrm{n}}=[\mathrm{P}],
$$

where $\mathrm{P}_{\mathrm{i}}$ is the probability of the $\mathrm{i}$-th load, $[\mathrm{P}]$ is the permissible probability of an adverse event.

Most experts considered rare strong earthquakes, i.e. MDE in determining the combinatiuon coefficients. Until recently, these studies dealt with rail and road loads. In particular, G.S. Shestoperov considered combinations of seismic and road loads and recommended the following combination coefficients $\mathrm{K}_{\mathrm{eq}}=0.8-$ for the seismic load and $\mathrm{K}_{\mathrm{mr}}=0.3$ for the motor-road load [11]. These coefficients are included in the Russian Guidelines on earthquake-resistant construction. $\mathrm{K}_{\mathrm{eq}}=1$ and $\mathrm{K}_{\mathrm{tr}}=0.5$ were used for the combination of railway and seismic loads until 1972[12]. Since 1978, the combination coefficients $\mathrm{K}_{\mathrm{eq}}=0.7$ and $\mathrm{K}_{\mathrm{tr}}=0.8$ have been used [11]. These coefficients did not have an appropriate justification. In later studies, I. Kuznetsova and O. Sakharov [13] showed that the combination coefficients depend substantially on the bridge length and the situational seismicity (seismicity according to different maps of general seismic zoning). In different countries there exist studies of several types of loads such as seismic and wind, seismic and temperature, seismic and snow loads $[14,15]$. Similar studies have been carried out to design mobile communication towers in Irkutsk [16]. All these studies considered combinations of non-seismic loads with the MDE. The question of combinations of the railway load with the DE is only mentioned in the paper [13]. This problem is considered in more details below.

\section{Methods of research}

During the research the authors considered equiprobable pairs or triples of loads. To this aim the following equations were considered

$$
\begin{gathered}
\mathrm{P}_{1} \cdot \mathrm{P}_{2}=[\mathrm{P}], \\
\mathrm{P}_{1} \cdot \mathrm{P}_{2} \cdot \mathrm{P}_{3}=[\mathrm{P}],
\end{gathered}
$$

where $\mathrm{P}_{\mathrm{i}}$ is the probability of exceeding of the corresponding design level by the $\mathrm{i}$-th load; $[\mathrm{P}]$ is the allowable probability of a dangerous event.

By setting the probability of one or two (for two or three) loads and the permissible probability of the event, one can calculate the remaining load probability:

$$
\mathrm{P}_{2}=[\mathrm{P}] / \mathrm{P}_{1}
$$




$$
\mathrm{P}_{3}=[\mathrm{P}] / \mathrm{P}_{1} \cdot \mathrm{P}_{2}
$$

As a result, one-dimensional or two-dimensional dependences of one of the considered loads on the values of the other or two other loads are obtained. To estimate the load values, it is necessary to specify the distribution density functions (ddf) of each of the loads considered.

The authors considered the following pairs of load combinatons: seismic and road, seismic and railway, seismic and wind ones, as well as their possible triples. For the wind load, the Weibull distribution law was used [16]. The distribution of the railway load was used in accordance with the recommendations of [13], and for the car load the log-normal distribution law was used. In contrast to previous studies, different values of the permissible probability $[\mathrm{P}]$ were taken. For the MDE this probability was excepted as $[\mathrm{P}]=0.1$ per 100 years, and for the MD $[\mathrm{P}]=0.632$ per 100 years, which corresponds to the frequency of events every 1000 and every 100 years respectively. Similarly, you can get to multi-level designing, where 3-4 values of the permissible probability are used, instead of two. In particular, one can consider strong, moderate or weak earthquakes, as suggested by Fardis [6].

As an example, Fig. 1 shows the distribution function of the motor-road load $f(Q)$, described by the equation .

$$
f(Q):=\frac{1}{\beta \cdot Q \sqrt{2 \cdot \pi}} \cdot e^{-\left[\frac{1}{2} \cdot\left(\frac{\ln (Q)-\alpha}{\beta}\right)^{2}\right]}
$$

Here $\mathrm{Q}$ is the design motor-road load; $\beta$ and $\alpha$ are distribution parameters; $\beta=1.03 ; \alpha=$ $\ln (\mu)-\beta^{2} / 2$, where $\mu=75$ is the mathematical expectation of the load.

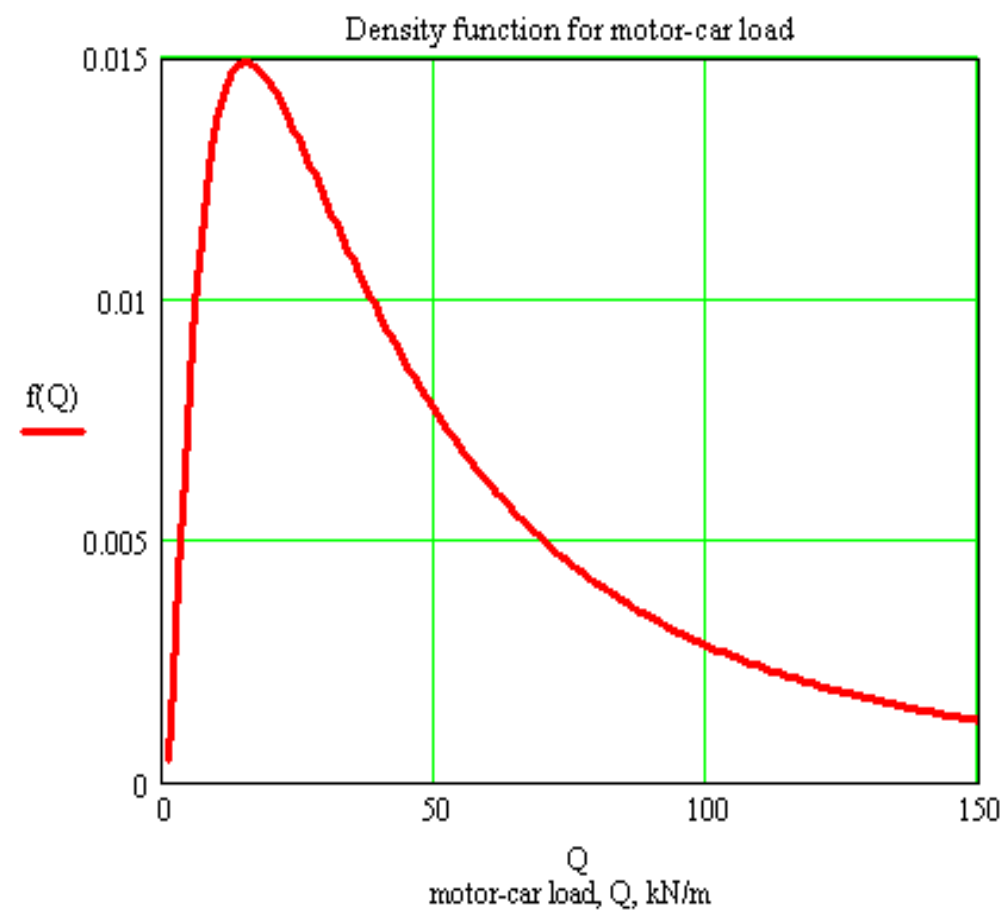

Fig. 1. Motor-road load distribution function. 
Table 1 shows the characteristics of the load under consideration

Table 1. Statistical parameters of the motor-road load.

\begin{tabular}{|c|c|c|c|c|}
\hline \multirow{2}{*}{$\begin{array}{c}\text { The design } \\
\text { motor-road } \\
\text { load } \mathrm{Q} \text {, } \\
\mathrm{kN} / \mathrm{m}\end{array}$} & \multirow{2}{*}{$\begin{array}{l}\text { The probability of } \\
\text { exceeding the } \\
\text { design motor-road } \\
\text { load, } P(Q)\end{array}$} & \multirow{2}{*}{$\begin{array}{c}\text { Combination } \\
\text { coefficient for } \\
\text { motor-road load } \\
\mathrm{K}_{\mathrm{Q}}\end{array}$} & \multicolumn{2}{|c|}{$\begin{array}{l}\text { Permissible probability of exceeding } \\
\text { the design seismic load } \mathrm{P}_{\mathrm{eq}}=[\mathrm{P}] / \mathrm{P}(\mathrm{Q})\end{array}$} \\
\hline & & & $\mathrm{DE} ;[\mathrm{P}]=0.632$ & $\mathrm{MDE} ;[\mathrm{P}]=0.1$ \\
\hline 0 & 0.894 & 0.071 & 0.707 & 0.112 \\
\hline 1 & 0.747 & 0.143 & 0.846 & 0.134 \\
\hline 2 & 0.615 & 0.214 & \multirow{12}{*}{$\begin{array}{l}\text { With this motor- } \\
\text { car load, the DE } \\
\text { is not combined }\end{array}$} & 0.163 \\
\hline 3 & 0.507 & 0.286 & & 0.197 \\
\hline 4 & 0.42 & 0.357 & & 0.238 \\
\hline 5 & 0.351 & 0.429 & & 0.285 \\
\hline 6 & 0.296 & 0.5 & & 0.338 \\
\hline 7 & 0.25 & 0.571 & & 0.399 \\
\hline 8 & 0.213 & 0.643 & & 0.469 \\
\hline 9 & 0.182 & 0.714 & & 0.549 \\
\hline 10 & 0.156 & 0.786 & & 0.64 \\
\hline 11 & 0.134 & 0.857 & & 0.745 \\
\hline 12 & 0.116 & 0.929 & & 0.864 \\
\hline 13 & 0.1 & 1 & & 1 \\
\hline
\end{tabular}

The last two columns in Table 1 are the permissible probabilities of exceeding the design value of PGA for DE and MDE by the seismic load. Calculations of PGA, depending on the permissible probability of exceeding them, were carried out earlier by OA Sakharov [16,17]. However, in these studies, the old seismic scale [23] was used, which prescribed a doubling of the loads with an increase of seismicity by one, i.e. taking the values of PGA 1, 2 and $4 \mathrm{~m} / \mathrm{s}^{2}$, respectively, for intensity 7,8 and 9 on the MSK scale. At present, F.Aptikaev has developed a new instrumental part of the seismic scale [18], in which the data [18] are based on representative statistical material and are consistent with the available studies of other experts [19]. Therefore, the authors had to develop a new method of estimating the design PGA based on a new seismic scale. This method includes 5 stages

1. Estimating seismic hazard parameters of the building site using a given situational seismicity (seismicity at the maps of general seismic zoning). For this purpose the wellknown relation [20] between the repeatability $\mathrm{T}$ of the action and its intensity I on the MSK scale was used. This relation is described by the following equation:

$$
\log T=a I+b
$$

Parameters $a$ and $b$ are determined from the given intensity values I and the frequency T of seismic actions, using the least squares method [21].

2. Using the values of $a$ and $b$ obtained in point 1 and the given probability of exceeding $[\mathrm{P}]$, we determine the design earthquake frequency, basing on the distribution of the earthquake event stream according to Poisson's law [20]

$$
T_{\text {calc }}=-\frac{T_{\text {life }}}{\ln (1-[P])}
$$

3. On the basis of the obtained parameters $\mathrm{a}$ and $\mathrm{b}$ and the design repeatability $\mathrm{T}_{\text {calc }}$, using formula (7), we determine the estimated design intensity $I_{\text {calc }}$ 


$$
I_{\text {calc }}=\frac{\log \left(T_{\text {calc }}\right)-b}{a}
$$

4. Using the obtained value of $\mathrm{I}_{\text {calc }}$ and the new seismic scale, one can determine the design value of PGA. For this purpose, the authors obtained the following approximation PGA (I)

$$
P G A=C_{0}+C_{1} \cdot\left(e^{(-\alpha \cdot I)}+C_{2} \cdot e^{(-\beta \cdot I)}\right),
$$

where $\mathrm{C}_{0}=0.037 ; \mathrm{C}_{1}=-0.019 ; \mathrm{C}_{2}=-0.946 ; \alpha=-0.765 ; \beta=-0.806$

5. The PGA values obtained by formula (10) are typical for oscillation periods of $\mathrm{T}_{\mathrm{eq}} \sim 0.3$ $\mathrm{s}$. In the general case, they depend on the input prevailing period $\mathrm{T}_{\mathrm{eq}}[19,22]$, therefore the acceleration obtained by formula (10) is to be corrected by introducing the respective corrective factor $\mathrm{K}_{\mathrm{PGA}}$. This correction was obtained by the authors according to the data of [19] and can be written in the following form:

$$
K_{P G A}=C^{p}{ }_{0}+C^{p} \cdot\left(e^{\left(-\alpha^{p} \cdot T_{e q}\right)}+C^{p} \cdot e^{\left(-\beta^{p} \cdot T_{e q}\right)}\right),
$$

where $\mathrm{C}_{0}=-63.592 ; \mathrm{C}_{1}=69.599 ; \mathrm{C}_{2}=-0.009 ; \alpha^{\mathrm{p}}=0.029 ; \beta^{\mathrm{p}}=3.295$

The corresponding procedure has been carried out for each value of the permissible probability $\mathrm{P}_{\mathrm{eq}}$ from Table 1 . As a result, the design PGA values for each load have been obtained. The combination coefficient of the seismic load is obtained by dividing the design acceleration value by its maximum value. The calculation results are presented graphically in Fig. 2 in the form of the dependence of the combination coefficient of the seismic load on the analogous coefficient of the motor-road load.

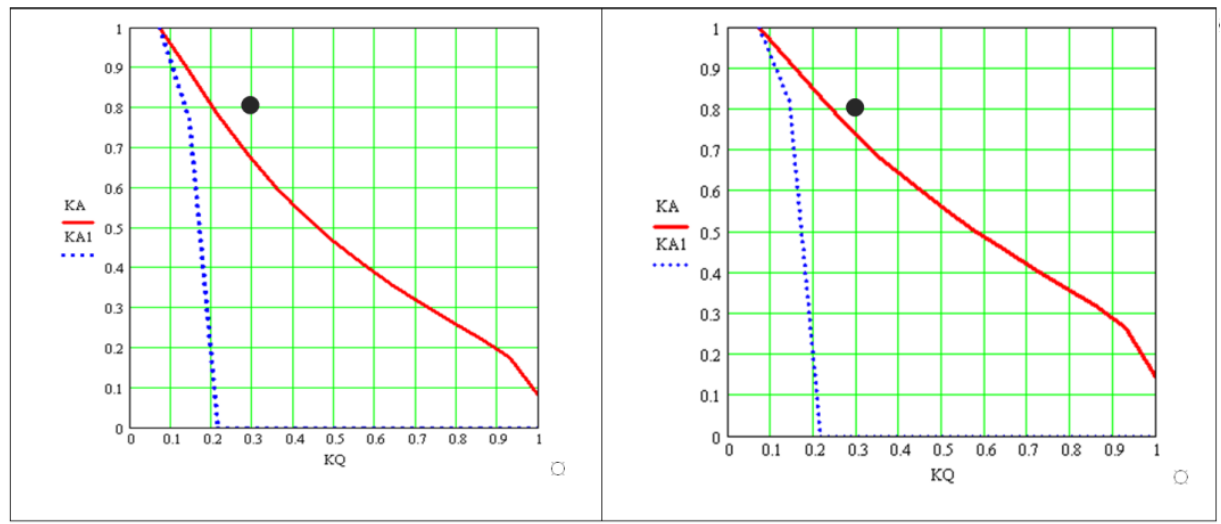

Fig. 2. Dependence of the combination coefficient of seismic load on the combination coefficient of motor-road load; the values of combination coefficients in accordance with the Guidelines in law are marked by a black point.

\section{Result and discussion}

The results obtained show that the combination coefficients for DE and MDE vary essentially. In the examples considered, for car loads exceeding $80 \%$ of the design value the combination with the seismic load is not required. The combination coefficients recommended in the Russian Guidelines in law, can be used only for the MDE. When comparing the combination coefficients for building sites with different situational seismicity, their values are found to be close, although the loads themselves differ substantially. The values of combination coefficients depend on the frequency of the design 
actions. At increasing the frequency of DE up to 300 years and MDE up to 3000 years the combination coefficients increase significantly. This result should be taken into account by the customers and designers when considering load combinations.

An analysis of foreign investigations [14,15] shows that the combination coefficients were previously considered only for the MDE. In the presented investigations, the combination coefficients for the DE were also analyzed and calculated. Similar studies [13] carried out for railway bridges show that the combination coefficients for the DE are smaller then for MDE or not needed at all.

\section{Conclusions}

The research carried out allows one to draw the following conclusions:

1. Combination coefficients for PBD should be calculated separately for each input level. For the DE and the MDE they vary significantly.

2 . The values of the combination coefficients are determined mainly by the frequency of the design actions and to a lesser extent they depend on the seismic activity of the building site.

\section{References}

1. I.I. Goldenblat, N.A. Nikolaenko, S.V. Polyakov, S.V. Ulyanov, Models of structure seismic resistances (Stroiizdat, Moscow, 1979)

2. Ya.M. Eisenberg, L.Sh. Kilimnik, The collected papers "Earthquake stability of buildings and engineer structures" (Moscow, Stroyizdat, 1972)

3. L.Sh. Kilimnik, Construction mechanics and structure calculations 2, 40-44 (1975)

4. D.J. Dowric, Earthquake resistant Design for Engineers and architects (John Wiley \& Sons, New York, 1977)

5. R. Park, T. Paulay, Reinforced Concrete Structures (John Wiley \& Sons, New York, 1975)

6. M.N. Fardis, Elsevier Science Ltd. 12th European Conference on Earthquake Engineering 845 (2002)

7. V. Foravante, G. Madabhushi, A.V. Benin, S.V. Elizarov, A.M. Uzdin, I.A. Fedotova, A.A. Dolgaya, O.A. Sakharov, Performance based designing of high-rise base isolated buildings (International workshop "Base isolated high-rise buildings", Yerevan, 2008)

8. European Standard Eurocode 8. Design of structures for earthquake resistance

9. V.V. Bolotin, Statistical methods in structural mechanics (Gosstroiizdat, Moscow, 1961)

10. A.R. Rzhanitsyn, Theory of calculating building structures for reliability (Stroyizdat, Moscow, 1978)

11. G.S. Shestoperov, Seismic stability of bridges (Transport, Moscow, 1984)

12. G.P. Peredery, Course of bridges (Transzheldorizdat, 1945)

13. I.O. Kuznetsova, O.A. Sakharov, Earthquake engineering 3, 21-25 (2006)

14. Y.J. Yin, Y. Li, Snow and earthquake load combination considering snow accumulation The 14th World Conference on Earthquake Engineering, Beijing, China (2008) 
15. S. Maleki, A. Maghsoudi-Barmi, International Journal of Structural Stability and Dynamics 16, 1550020 (2016)

16. O.A. Sakharov, Earthquake engineering. Safety of structures 2, 10-14 (2005)

17. O.A. Sakharov, Earthquake engineering. Safety of structures 4, 7-9 (2004)

18. F.F. Aptikayev, Instrumental scale of seismic intensity (Science and Education, Moscow, 2012)

19. M.A. Bogdanova, O.P. Nesterova, N.V. Nikonova, A.S. Tkachenko, A.M. Uzdin, M. Rakhmanova, T.M. Azayev, Kh.R. Zaynulabidova, Science and world 3(43):1, 49-55 (2017)

20. Y.V. Riznichenko, Seismic shaking of the USSR territory (Science, Moscow, 1979)

21. A.M. Uzdin, V.G. Vorobyov, M.A. Bogdanova, V.V. Sigidov, S.S. Vanicheva, Economics of earthquake engineering (FGPU DPO "Educational and Methodological Center for Education in Railway Transport", Moscow, 2017)

22. A.A. Dolgaya, VNIINTPI. Ser. "Earthquake engineering" 5-6, 56-63 (1994)

23. Russian Federation Standard GOST 6249-52 